\title{
Papua New Guinean
}

National Cancer Institute

\section{Source}

National Cancer Institute. Papua New Guinean. NCI Thesaurus. Code C43411.

Denotes the inhabitants of Papua New Guinea, a person from there, or their descendants elsewhere. 